\title{
Response to depression treatment in the Aging Brain Care Medical Home model
}

This article was published in the following Dove Press journal:

Clinical Interventions in Aging

31 October 2016

Number of times this article has been viewed

\author{
Michael A LaMantia ${ }^{1-4}$ \\ Anthony J Perkins ${ }^{5,6}$ \\ Sujuan $\mathrm{GaO}^{2,7}$ \\ Mary G Austrom 8,9 \\ Cathy A Alder ${ }^{10}$ \\ Dustin D French ${ }^{11,12}$ \\ Debra K Litzelman'2,3,13 \\ Ann $\mathrm{H}_{\text {Cottingham }}^{3}$ \\ Malaz A Boustani ${ }^{1-3,5}$
}

'Indiana University Center for Aging

Research, ${ }^{2}$ Regenstrief Institute, Inc.,

${ }^{3}$ Department of Medicine, Indiana

University School of Medicine,

Indianapolis, IN, ${ }^{4}$ Department of

Medicine, University of Vermont

College of Medicine, Burlington,

VT, ${ }^{5}$ Indiana University Center for

Health Innovation and Implementation

Science, ${ }^{6}$ Indiana Clinical and

Translational Sciences Institute,

${ }^{7}$ Department of Biostatistics, Indiana

University School of Medicine,

${ }^{8}$ Department of Psychiatry, Indiana

University School of Medicine, 'Indiana

University Alzheimer's Disease Center,

${ }^{10}$ Eskenazi Health, Indianapolis, IN,

"Department of Ophthalmology,

Feinberg School of Medicine,

Northwestern University, ${ }^{12}$ Veterans

Affairs Health Services Research and

Development Service, Chicago, IL,

${ }^{13}$ Indiana University Center for Health

Services and Outcomes Research,

Indianapolis, IN, USA

Correspondence: Michael A LaMantia Department of Medicine, Robert Larner, MD College of Medicine, University of Vermont, 89 Beaumont Avenue, Given Courtyard, 4th Floor, Burlington, VT 05405, USA

Tel + I 8026564560

Fax +I 8026564576

Email michael.lamantia@uvmhealth.org
Objective: To evaluate the effect of the Aging Brain Care (ABC) Medical Home program's depression module on patients' depression severity measurement over time.

Design: Retrospective chart review.

Setting: Public hospital system.

Participants: Patients enrolled in the ABC Medical Home program between October 1, 2012 and March 31, 2014.

Methods: The response of 773 enrolled patients who had multiple patient health questionnaire- 9 (PHQ-9) scores recorded in the ABC Medical Home program's depression care protocol was evaluated. Repeatedly measured PHQ-9 change scores were the dependent variables in the mixed effects models, and demographic and comorbid medical conditions were tested as potential independent variables while including random effects for time and intercept.

Results: Among those patients with baseline PHQ-9 scores $>10$, there was a significant decrease in PHQ-9 scores over time $(P<0.001)$; however, the effect differed by gender $(P=0.015)$. On average, women's scores (4.5 point drop at 1 month) improved faster than men's scores ( 1 point drop at 1 month). Moreover, both men and women had a predicted drop of 7 points $(>50 \%$ decline from baseline) on the PHQ-9 at 6 months.

Conclusion: These analyses demonstrate evidence for the sustained effectiveness of the ABC Medical Home program at inducing depression remission outcomes while employing clinical staff who required less formal training than earlier clinical trials.

Keywords: geriatrics, care coordination, Medicare

\section{Introduction}

Depression among older adults is common, a major cause of disability, and is associated with increased mortality. ${ }^{1-3}$ The rate of major depression in community-dwelling older adults is $\sim 2 \%,{ }^{4}$ although the rates are higher among hospitalized individuals. ${ }^{5}$ Minor depression is more common still with rates varying from $9.8 \%$ among seniors dwelling in the community to $14 \%-25 \%$ among older adults who are hospitalized. ${ }^{4,5}$ Depression is associated with costs that accrue to society, families, and individuals by a variety of mechanisms, including lost productivity, time away from work, costs for the treatment of depression in patients, and increased costs for treating comorbid conditions in patients. ${ }^{3,6}$ Due to its prevalence, burden, and associated costs, depression has become a major target condition for health programs that wish to improve the care of older adults.

However, psychiatrists with specialized training in geriatric mental health to treat these older adults are in short supply. ${ }^{7}$ Indeed, the majority of mental health care in the USA is provided not by mental health professionals but by general medical care providers and is considered inadequate. ${ }^{8}$ Interventions that support primary care physicians in 
providing effective care to older adults with depression have been developed and shown to be effective in a large, multisite randomized controlled trial. ${ }^{9}$ In translating the findings from randomized controlled trials to active clinical practice, adaptations are frequently needed.$^{10}$ In 2008, the Improving MoodPromoting Access to Collaborative Treatment (IMPACT) model of depression care was successfully implemented in the Healthy Aging Brain Center clinical venue with positive results. ${ }^{11}$ Though effective, this model was limited by its requirement that patients present to the clinic for care and was not considered scalable due to limitations in the number of available care providers. As a result, in 2010 the Aging Brain Care (ABC) Medical Home program was developed, which employs a mobile and versatile workforce that can meet patients in their home environment. ${ }^{12,13}$

This investigation evaluated the effect of the $A B C$ Medical Home program's depression module on patients' depression severity measurement over time. Specifically, the change in patient health questionnaire-9 (PHQ-9) score over time was investigated, stratified by the initial score. Additionally, clinical predictors were identified for response to the program's depression intervention.

\section{Methods}

\section{Study design and setting}

This was an analysis of depression care data from the $\mathrm{ABC}$ Medical Home, a program designed to augment the care that is provided by primary care physicians to older adults with late-life depression and/or dementia. The design and evolution of the program have been described previously. ${ }^{12-14}$ The program is notable for several features that are reviewed briefly here that differentiate it from other clinical care programs. First, the majority of care in the ABC Medical Home is provided by care coordinator assistants (CCAs), persons selected for their ability to communicate and desire to work with older adults. ${ }^{15,16}$ These CCAs have primarily high school and 2-year college education, rather than more advanced degrees, and so represent the program's strategy to create a more scalable geriatric care workforce to meet the care needs of the nation's growing population of seniors. CCAs are supervised by a team of nurses and social workers, skilled in the care of older adults, and overseen by a geriatric medical director. Second, the program has provided training in the IMPACT model of depression care and in advanced dementia care practices to the CCAs, nurses, and social workers. IMPACT is a collaborative care model of depression care that utilizes care managers to support primary care providers in adopting a systematic approach to the treatment of patients' depressive symptoms. ${ }^{9}$ CCAs, social workers, and nurses received training in the principles of the IMPACT model of care from the University of Washington's AIMS Center. In line with this training, the team members practice measurement-based care and use validated instruments, the PHQ-9 for depression and the Healthy Aging Brain Center Monitor (HABC-M) for dementia, to track patient response to clinical interventions. ${ }^{17,18}$ Finally, the team members record PHQ-9 and HABC-M scores of the patients in the electronic medical record-ABC, the tracking software of the program. ${ }^{19}$ In this manner, they can easily monitor responses of individual patients to the interventions longitudinally as well as the overall health of their assigned panel of patients.

Results of this program that was centered at Eskenazi Health (formerly Wishard Health Services), a safety-net, urban, public hospital, 10 community health centers located in Indianapolis, Indiana, and in the homes of patients who receive medical care at these facilities are presented here. As described previously, ${ }^{13} \mathrm{ABC}$ Medical Home team members provide services to patients and their caregivers in a variety of settings in order to maximize access. Ethical approval and patient written informed consent for participation in the program and analysis of the program's data were deemed not necessary by the Indiana University institutional review board as this work was determined to not constitute human subjects research.

\section{Program implementation}

The depression program of the ABC Medical Home is based on the IMPACT model of depression care. ${ }^{9}$ The identification and enrollment of patients and the ABC Medical Home depression intervention have been described previously..$^{13}$ All patients in the program were prospectively identified prior to enrollment in the program as having diagnoses of dementia, depression, or both, using International Classification of Disease, Ninth Revision codes of either condition and a visit to an Eskenazi Health care provider in the prior 24 months. Briefly, the depression intervention can be divided into three phases. During the first phase, the CCA initially visits the patient to stage their cognitive status using the PHQ-9, mini-mental state exam, and HABC-M. Following this visit, the CCA meets the team nurse and social worker to develop an individualized care plan for the patient, including referral for more extensive evaluation by memory care and mental health care specialists if deemed necessary. After this initial visit, a follow-up patient visit happens within 2-4 weeks to review the initial care plan and provide access to appropriate educational and community health resources. Patients with low-level depressive symptoms (PHQ-9 < 10) are offered behavioral activation and relapse prevention 
activities. Patients with symptoms consistent with major depression (PHQ-9 $\geq 10$ ) are offered problem-solving therapy by the team nurses and social workers. If patients are believed to be candidates for initiation or adjustment of pharmacologic antidepressant therapy, they are referred back to their primary care physicians. In the follow-up phase of the program, patient visits are organized every month for the first 3 months and then every 3 months thereafter. At each visit, depression symptoms of the patients are measured using the PHQ-9. Adjustments are made to the patient's plan of care by the CCA, nurse, and social worker based on the patient's scores on the PHQ-9 and other clinical information. During the acute care transition phase of the program, the ABC Medical Home team contacts inpatient hospital care providers if the patient is hospitalized and shares relevant physical, cognitive, and mental health background information to aid in the patient's care. During the patient's hospital discharge, the patient's care coordinator seeks to meet the patient within $72 \mathrm{~h}$ to perform medication reconciliation and coordinate post-discharge care planning.

\section{Statistical analysis}

In this analysis, the responses of patients enrolled in the $\mathrm{ABC}$ Medical Home depression care protocol were evaluated. First, chi-square tests and Wilcoxon rank sum tests were used to compare the demographics and clinical characteristics, including comorbidities, of patients who had multiple PHQ-9 scores and those who had only one PHQ-9 score recorded in their clinical record. Next, chi-square tests were utilized to compare demographics and comorbid conditions in patients with multiple PHQ-9 evaluations divided into three groups by baseline PHQ-9 scores (0-4, 5-9, or $\geq 10)$. Mixed effects models were used separately for the three groups of patients based on their baseline PHQ-9 scores. Repeatedly measured PHQ-9 change scores were the dependent variables in the mixed effects models, and the demographic and comorbid medical conditions were tested as potential independent variables while including random effects for time and intercept. Comparable results were obtained when running similar models using PHQ-9 scores as the outcome while adjusting for the baseline PHQ-9 score. Since the results were similar, those using the change score are only reported. All the analyses were performed using SAS v9.3 and $P<0.05$ was considered statistically significant.

\section{Results}

Between October 1, 2012 and March 31, 2014, 1,621 patients were enrolled in the ABC Medical Home program's registry and had their clinical data registered in the electronic medical record for the ABC Medical Home program at Eskenazi Health. During this 18-month period, 871 (54\%) patients had at least one PHQ-9 assessment recorded. Seven hundred and seventy-three of these 871 patients $(89 \%)$ had at least one additional PHQ-9 score recorded on a subsequent visit. Table 1 shows the demographic and clinical characteristics of patients who either had or did not have a subsequent PHQ-9 score recorded after their baseline PHQ-9 score. Patients who subsequently had PHQ-9 scores recorded in their chart were younger, had a higher proportion of depression recorded in their chart as a medical comorbidity, had higher baseline PHQ-9 scores, and had lower rates of either congestive heart failure (CHF) or dementia.

Table 2 shows the association of baseline PHQ-9 scores by strata with demographics and comorbid conditions of the 773 patients with subsequent PHQ-9 scores recorded. Women tended to have higher baseline PHQ-9 scores, as did patients of White race and younger age. Patients with chronic obstructive pulmonary disease, depression recorded in their chart, and taking antidepressants also tended to have higher incidences of baseline PHQ-9 scores $\geq 10$. The vast majority of visits in this program were performed by CCAs, both at the initial visit and at subsequent visits. Nurses and social workers participated in return visits more frequently when patients had higher initial PHQ-9 scores.

Table I Association of PHQ-9 follow-up status with demographics and comorbid conditions

\begin{tabular}{llll}
\hline Characteristic & $\begin{array}{l}\text { PHQ-9 on } \\
\text { additional } \\
\text { visits (n=773) }\end{array}$ & $\begin{array}{l}\text { No PHQ-9 } \\
\text { on additional } \\
\text { visits (n=98) }\end{array}$ & P-value \\
\hline Female (\%) & 79.4 & 77.6 & 0.665 \\
Race & & & 0.469 \\
$\quad$ African-American (\%) & 51.3 & 58.0 & \\
Other (\%) & 3.2 & 3.4 & \\
White (\%) & 45.5 & 38.6 & \\
Age & & & \\
65-69 years (\%) & 37.0 & 25.5 & \\
70-74 years (\%) & 27.6 & 18.4 & \\
75-79 years (\%) & 18.2 & 25.5 & \\
80+ years (\%) & 17.2 & 30.6 & \\
Diabetes (\%) & 58.2 & 55.1 & 0.556 \\
CAD (\%) & 38.0 & 38.8 & 0.887 \\
CHF (\%) & 31.4 & 42.9 & 0.023 \\
Stroke (\%) & 31.4 & 35.7 & 0.392 \\
Cancer (\%) & 28.6 & 24.5 & 0.395 \\
COPD (\%) & 31.2 & 32.6 & 0.767 \\
Depression (\%) & 82.4 & 73.5 & 0.032 \\
Dementia (\%) & 12.2 & 23.5 & 0.002 \\
Renal disease (\%) & 19.7 & 20.4 & 0.862 \\
Arthritis (\%) & 8.3 & 3.1 & 0.071 \\
Mean baseline PHQ-9 (\%) & $5.5(5.1)$ & $4.4(4.8)$ & 0.025 \\
\hline Abbrevions:PHQ-9, & & \\
\hline
\end{tabular}

Abbreviations: $\mathrm{PHQ}-9$, patient health questionnaire-9; $\mathrm{CAD}$, coronary artery disease; $\mathrm{CHF}$, congestive heart failure; COPD, chronic obstructive pulmonary disease. 
Table 2 Association of baseline PHQ-9 score with demographics and comorbid conditions (N=773)

\begin{tabular}{|c|c|c|c|c|}
\hline Characteristic & \% PHQ-9 (0-4) & \% PHQ-9 (5-9) & $\%$ PHQ-9 ( $\geq 10)$ & $P$-value \\
\hline Overall (n=773) & 51.9 & 27.8 & 20.3 & \\
\hline \multicolumn{4}{|l|}{ Gender } & $<0.001$ \\
\hline Male $(n=159)$ & 63.5 & 26.4 & 10.1 & \\
\hline Female $(n=6 \mid 4)$ & 48.9 & 28.2 & 23.0 & \\
\hline \multicolumn{4}{|l|}{ Race } & 0.045 \\
\hline Black $(n=357)$ & 57.4 & 25.6 & 16.8 & \\
\hline Other $(n=22)$ & 31.8 & 45.4 & 22.7 & \\
\hline White $(n=3 \mid 7)$ & 49.5 & 26.5 & 24.0 & \\
\hline \multicolumn{4}{|l|}{ Age } & $<0.001$ \\
\hline $65-69$ years $(n=286)$ & 42.5 & 28.9 & 18.3 & \\
\hline $70-74$ years $(n=213)$ & 56.4 & 26.3 & 10.2 & \\
\hline $75-79$ years $(n=|4|)$ & 66.1 & 23.7 & 5.1 & \\
\hline $80+$ years $(n=133)$ & 67.0 & 23.9 & 6.7 & \\
\hline \multicolumn{4}{|l|}{ Diabetes } & 0.766 \\
\hline No $(n=323)$ & 51.4 & 29.1 & 19.5 & \\
\hline Yes $(n=450)$ & 52.2 & 26.9 & 20.9 & \\
\hline \multicolumn{4}{|l|}{ CAD } & 0.915 \\
\hline No $(n=479)$ & 52.2 & 28.0 & 19.8 & \\
\hline Yes $(n=294)$ & 51.4 & 27.6 & 21.1 & \\
\hline \multicolumn{4}{|l|}{$\mathrm{CHF}$} & 0.100 \\
\hline No $(n=530)$ & 54.3 & 27.0 & 18.7 & \\
\hline Yes $(n=243)$ & 46.5 & 29.6 & 23.9 & \\
\hline \multicolumn{4}{|l|}{ Stroke } & 0.986 \\
\hline No $(n=530)$ & 52.1 & 27.7 & 20.2 & \\
\hline Yes $(n=243)$ & 51.4 & 28.0 & 20.6 & \\
\hline \multicolumn{4}{|l|}{ Cancer } & 0.395 \\
\hline No $(n=552)$ & 53.1 & 26.4 & 20.5 & \\
\hline Yes $(n=22 I)$ & 48.9 & 31.2 & 19.9 & \\
\hline \multicolumn{4}{|l|}{ COPD } & 0.027 \\
\hline No $(n=532)$ & 55.1 & 25.6 & 19.4 & \\
\hline Yes $(n=24 I)$ & 44.8 & 32.8 & 22.4 & \\
\hline \multicolumn{4}{|l|}{ Depression } & $<0.001$ \\
\hline No $(n=136)$ & 71.3 & 23.5 & 5.2 & \\
\hline Yes $(n=637)$ & 47.7 & 28.7 & 23.6 & \\
\hline \multicolumn{4}{|l|}{ Dementia } & 0.038 \\
\hline No $(n=679)$ & 50.4 & 28.1 & 21.5 & \\
\hline Yes $(n=94)$ & 62.8 & 25.5 & 11.7 & \\
\hline \multicolumn{4}{|l|}{ Renal disease } & 0.336 \\
\hline No $(n=62 I)$ & 51.2 & 28.8 & 20.0 & \\
\hline Yes $(n=152)$ & 54.6 & 23.7 & 21.7 & \\
\hline \multicolumn{4}{|l|}{ Arthritis } & 0.525 \\
\hline No $(n=709)$ & 52.5 & 27.5 & 20.2 & \\
\hline Yes $(n=64)$ & 45.3 & 32.8 & 21.9 & \\
\hline \multicolumn{4}{|l|}{ Antidepressant } & $<0.001$ \\
\hline No $(n=228)$ & 64.5 & 25.4 & 10.1 & \\
\hline Yes $(n=552)$ & 45.8 & 28.9 & 25.3 & \\
\hline \multicolumn{4}{|c|}{ Care provider type at initial visit } & 0.801 \\
\hline CCA (\%) & 98.2 & 98.1 & 96.8 & \\
\hline NP (\%) & 0.8 & 0.9 & 1.9 & \\
\hline SW (\%) & 1.0 & 0.9 & 1.3 & \\
\hline \multicolumn{5}{|c|}{ Care provider type at patients' subsequent visits } \\
\hline CCA (\%) & 99.7 & 99.1 & 98.7 & 0.329 \\
\hline NP (\%) & 2.3 & 4.3 & 11.2 & $<0.001$ \\
\hline $\mathrm{RN}(\%)$ & 0.3 & 0.0 & 0.7 & 0.486 \\
\hline SW (\%) & 1.5 & 2.4 & 9.9 & $<0.001$ \\
\hline
\end{tabular}

Abbreviations: CCA, care coordinator assistant; NP, nurse practitioner; RN, registered nurse; SW, social worker; PHQ-9, patient health questionnaire-9; CAD, coronary artery disease; $\mathrm{CHF}$, congestive heart failure; COPD, chronic obstructive pulmonary disease. 
Table 3 presents mixed model results with factors associated with PHQ-9 change scores over time in the three patient groups defined by baseline PHQ-9 scores. A decreased PHQ-9 change score indicates clinical improvement, whereas an increased PHQ-9 change score indicates a worsening of clinical symptoms. Among those with baseline PHQ-9 scores $\geq 10$, there was a significant decrease in PHQ-9 scores over time $(P<0.001)$; however, the effect differed by gender $(P=0.015)$. Figure 1 displays the predicted mean PHQ-9 change scores over time in both men and women. On average, women's scores (4.5 point drop at 1 month) improved faster than men's scores (1 point drop at 1 month). However, both men and women had a predicted drop of 7 points on the PHQ- 9 at 6 months. At 12 months, men had on an average predicted drop on the PHQ-9 of 7 points while women experienced a predicted drop of 8 points. A 7-point decline is slightly $>50 \%$ decline from the baseline average PHQ-9 score of 13.6 points for this stratum.

Among those with baseline PHQ-9 scores of 5-9, changes in PHQ-9 scores over time differed by history of CHF $(P=0.010)$. In patients without CHF, predicted PHQ-9 scores were $\sim 1$ point less than those with CHF. However, over time the PHQ-9 score remained relatively consistent in those with CHF while those without CHF continued to have improving PHQ-9 change scores over time. At 12 months, the predicted PHQ-9 change scores of patients without $\mathrm{CHF}$ were $\sim 1$ point higher than those with CHF. Use of an antidepressant was associated with lower PHQ-9 changes, but this effect did not vary over time (Figure 2).

Finally, among those with initial PHQ-9 scores from 0 to 4, no significant change in PHQ-9 scores was seen for

Table 3 Mixed model results for PHQ-9 change over time

\begin{tabular}{lll}
\hline Baseline PHQ-9 & $\begin{array}{l}\text { Estimate (SE) } \\
\text { (Regression (beta) coefficient) }\end{array}$ & P-value \\
\hline$\geq 10$ & & $<0.001$ \\
Time & $2.152(0.503)$ & 0.001 \\
Time squared & $-0.124(0.038)$ & 0.055 \\
Any stroke & $-1.493(0.773)$ & 0.006 \\
Female & $5.264(1.891)$ & 0.005 \\
Female $\times$ time & $-1.513(0.535)$ & 0.015 \\
Female $\times$ time squared & $0.100(0.04 I)$ & \\
$5-9$ & & $<0.001$ \\
Time & $0.210(0.039)$ & 0.005 \\
Antidepressants & $-1.186(0.419)$ & 0.029 \\
CHF & $1.146(0.522)$ & 0.010 \\
CHF $\times$ time & $-0.167(0.065)$ & \\
$0-4$ & & 0.090 \\
Time & $-0.034(0.020)$ & $0.38 I$ \\
CHF & $-0.270(0.308)$ & 0.001 \\
CHF $\times$ time & $0.120(0.036)$ & \\
\hline
\end{tabular}

Abbreviations: PHQ-9, patient health questionnaire-9; SE, standard error; CHF, congestive heart failure. patients without $\mathrm{CHF}(P=0.958)$, but $\mathrm{CHF}$ affected patient's PHQ-9 response over time. For patients with and without CHF, the predicted PHQ- 9 change score was -0.5 (an average increase of 0.5 points from baseline). For patients without CHF, the change score remained relatively constant over time $(P=0.958)$, while patients with CHF showed improvement over time with $\sim 0.5$ points drop in PHQ-9 scores at 12 months (Figure 3).

\section{Discussion}

Results of the present analyses provide evidence for the effectiveness of the $\mathrm{ABC}$ Medical Home program at treating depressive symptoms in older adults as measured by PHQ-9. Depression response in the program is greatest among those patients who have the highest initial burden of symptoms and is similar in direction and magnitude to the effects seen in the earlier randomized control trial upon which this intervention was based. ${ }^{9}$ Unlike the original control trial however, the present program utilized services provided by CCAs and nurses, rather than psychologists and nurses, as a means of facilitating the program's reach to the community's large population of seniors. Interventions such as these provide initial evidence that effective care for geriatric syndromes can be provided in innovative ways utilizing team members who require less formal training than previous models.

Targeting of patients in a clinical intervention allows care providers to achieve efficiency, identifying those persons who are most likely to benefit from the program. In this program, discernable patterns of response to the intervention were identifiable. The highest response to treatment over time was observed among men and women who had the highest initial PHQ-9 scores with $>50 \%$ decline in PHQ-9 score among these patients at 6 months, although women's responses to the intervention occurred more quickly than men's responses. The present work stands in contrast to a previous report that women with higher severity of depression had a decreased response to cognitive behavioral therapy as compared to men, though the mechanism by which this occurs is yet to be fully elucidated. ${ }^{20}$ The effect of CHF on patients' response to the intervention was inconsistent among patients with different initial PHQ-9 scores. This may reflect differences in CHF severity that were not captured when the presence or absence of this condition was recorded. The observation that PHQ-9 scores remained low and did not appreciably increase among those subjects who had low PHQ-9 scores at their initial assessment was encouraging.

In the $\mathrm{ABC}$ Medical Home program, the majority of patient contacts were established by CCAs, rather than psychologists or nurses who provided the majority of the 


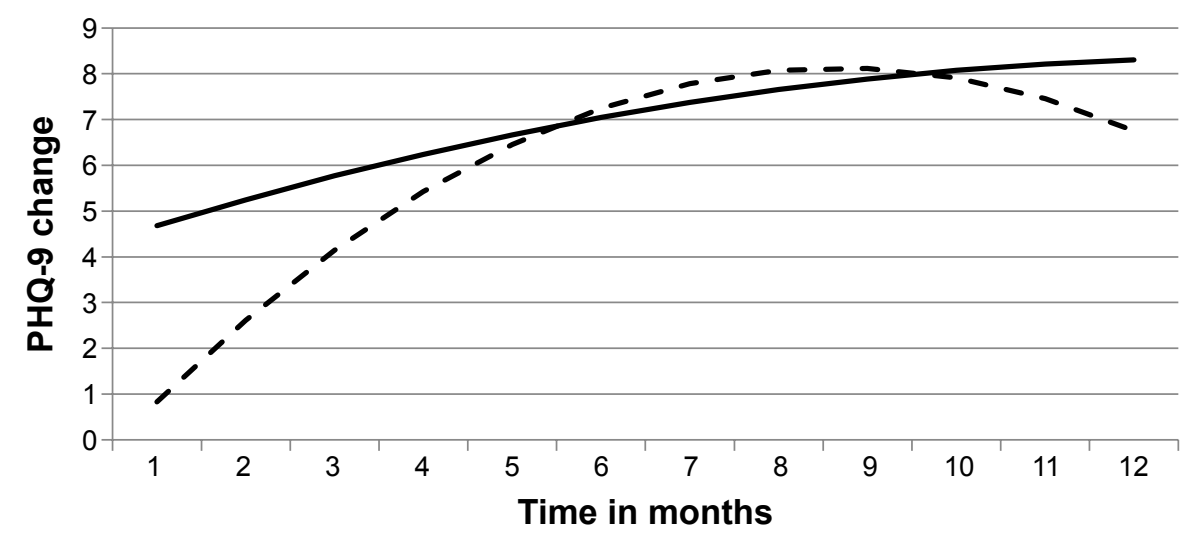

\section{- - Male predicted Female predicted}

Figure I Predicted PHQ-9 change* from mixed effects model for baseline PHQ-9 (I0+).

Note: $*$ Increase change score $=$ decrease in PHQ-9 (improving symptoms).

Abbreviation: PHQ-9, patient health questionnaire-9.

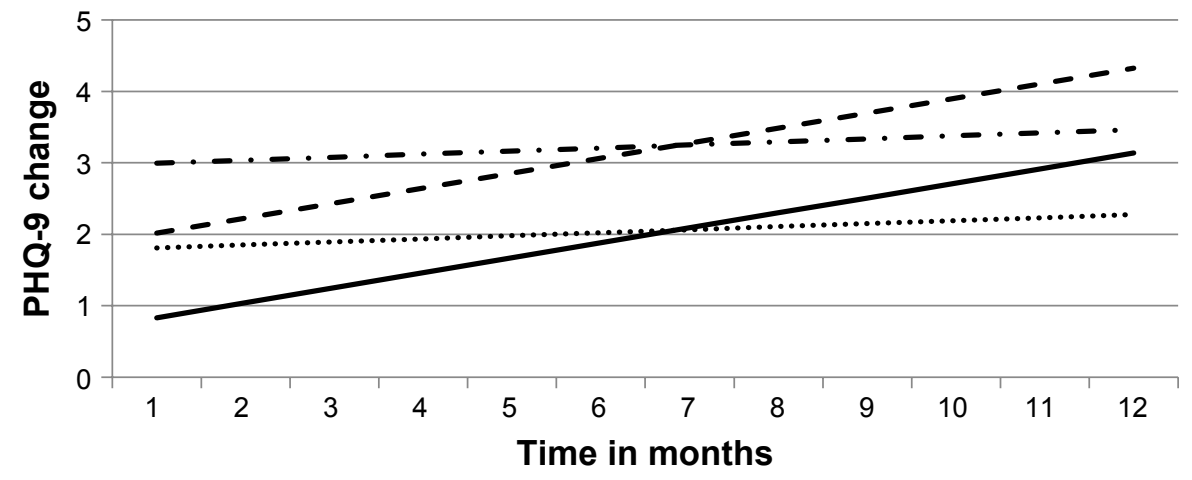

- - - No CHF predicted no antidepressant - - - CHF predicted no antidepressant

No CHF predicted antidepressant

........ CHF predicted antidepressant

Figure 2 Predicted PHQ-9 change from mixed effects model for baseline PHQ-9 (5-9).

Abbreviations: $\mathrm{PHQ}-9$, patient health questionnaire-9; $\mathrm{CHF}$, congestive heart failure.

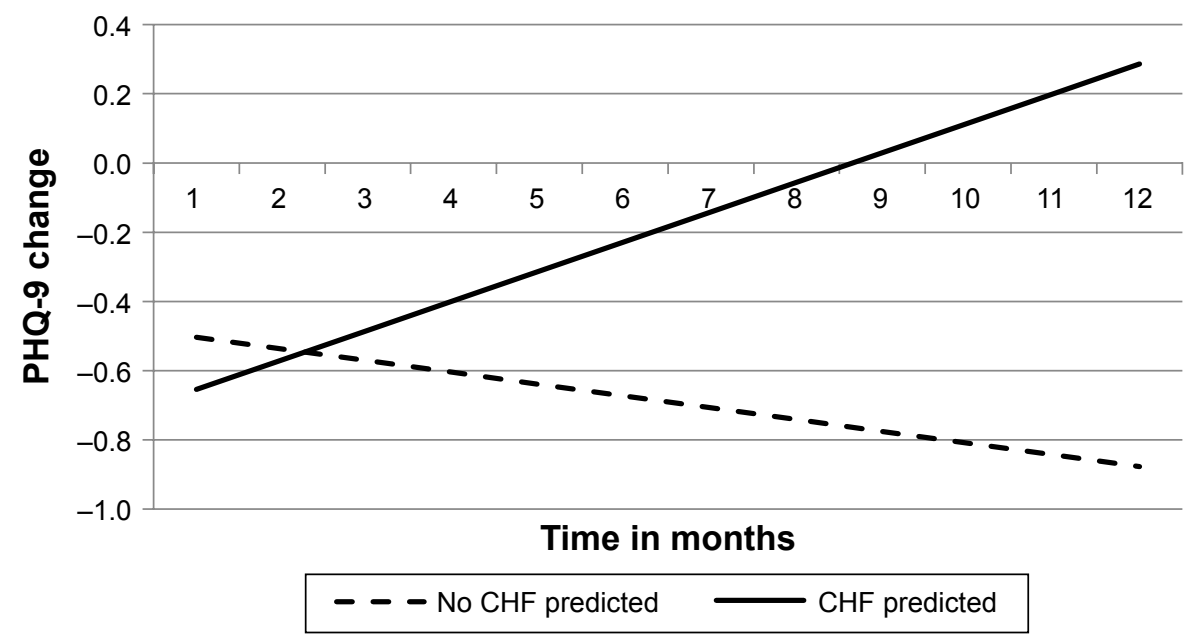

Figure 3 Predicted PHQ-9 change from mixed effects model for baseline PHQ-9 (0-4). Abbreviations: $\mathrm{PHQ}-9$, patient health questionnaire-9; CHF, congestive heart failure. 
intervention in the original IMPACT clinical trial. Nurses or social workers were most commonly involved directly in the care of patients whose PHQ-9 scores were the highest. While the cost savings for the present program is not reported and a separate financial analysis of this program's cost saving will be calculated in a separate independent analysis, the fact that the majority of the program's depression intervention is provided by team members without a professional medical or health degree is encouraging. This has important implications for the provision of care to the increasing number of older adults as the country must develop a geriatric mental health workforce to care for this population..$^{21-23}$

\section{Limitations}

This work has several limitations worth noting. First, the outcomes of a clinical program being administered in a health care system over time have been reported, rather than the results of a randomized trial conducted under static conditions. Second, some patients who had low-level depressive symptoms were enrolled in the program. As depression is a cyclical illness, patients with low-level depressive symptoms were recognized as being at risk of recurrence of their depression and offered relapse prevention activities. Additional information on psychiatric comorbidities beyond depression is unavailable and the effect of these conditions on patient response is unknown. Third, as this is an implementation program, there was no natural comparison group to study depression response among patients who did not receive the intervention. Still, this program is rooted in models of care that have been shown to be efficacious in earlier randomized controlled trials and the direction and magnitude of patient response are similar to the original clinical trial. Fourth, given that patient assessments were obtained by the same staff who were providing the clinical intervention, it is possible that an assessment bias could have been introduced into this work. Finally, as a population health management program, not all 1,621 patients who were enrolled in this program's registry were able to be seen and patients whom the clinical team were able to contact may differ from patients who could not be contacted, as discussed previously. ${ }^{13}$

\section{Conclusion}

The present analyses provide initial evidence for the sustained effectiveness of the ABC Medical Home program at inducing depression remission, as measured by $>50 \%$ decline in PHQ-9 scores among those with initial scores $\geq 10$, and achieving relapse prevention, averting an increase in depressive symptoms among patients with low PHQ-9 scores. In achieving these outcomes, the program employed clinical staff who required less formal training than those employed in earlier randomized trials. As such, this program provides a potential model for the expansion of the workforce of professionals trained in mental health to meet the needs of a growing population of older adults.

\section{Acknowledgments}

The project described was supported by Grant Number 1C1CMS331000-01-00 from the Department of Health and Human Services, Centers for Medicare \& Medicaid Services. This research was conducted by the awardee. Findings may or may not be consistent with or confirmed by the findings of the independent evaluation contractor. The contents of this publication are solely the responsibility of the authors and do not necessarily represent the official views of the U.S. Department of Health and Human Services or any of its agencies. Dr LaMantia additionally received support from grant 5K23 AG043498 and Dr Austrom received support from grant P30 AG010133 from the National Institute on Aging.

\section{Disclosure}

Dr LaMantia holds intellectual property rights in the electronic medical record system used by the ABC Medical Home program. Dr Boustani and Ms Alder hold intellectual property rights in the program's electronic medical record system as well as in the ABC Medical Home model. Dr Austrom, Dr Litzelman, and Ms Cottingham hold intellectual property rights in the $\mathrm{ABC}$ Medical Home model. These rights are managed by the Indiana University Research \& Technology Corporation (IURTC). Dr Boustani additionally holds equity in Preferred Population Health Management that is handling the distribution of the ABC Medical Home model. Neither the IURTC nor Preferred Population Health Management have funded this work. The remaining authors report no conflicts of interest in this work.

\section{References}

1. Laborde-Lahoz P, El-Gabalawy R, Kinley J, Kirwin PD, Sareen J, Pietrzak RH. Subsyndromal depression among older adults in the USA: prevalence, comorbidity, and risk for new-onset psychiatric disorders in late life. Int J Geriatr Psychiatry. 2015;30(7):677-685.

2. Almeida OP, Hankey GJ, Yeap BB, Golledge J, Norman PE, Flicker L. Depression, frailty, and all-cause mortality: a cohort study of men older than 75 years. J Am Med Dir Assoc. 2015;16(4):296-300.

3. Siu AL, Bibbins-Domingo K, Grossman DC, et al. Screening for depression in adults: US Preventive Services Task Force Recommendation Statement. JAMA. 2016;315(4):380-387.

4. Beekman A, Copeland J, Prince MJ. Review of community prevalence of depression in later life. Br J Psychiatry. 1999;174(4):307-311. 
5. Koenig HG, George LK, Peterson BL, Pieper CF. Depression in medically ill hospitalized older adults: prevalence, characteristics, and course of symptoms according to six diagnostic. Am J Psychiatry. 1997;154(10):1376-1383.

6. Unützer J, Patrick DL, Simon G, et al. Depressive symptoms and the cost of health services in HMO patients aged 65 years and older: a 4-year prospective study. JAMA. 1997;277(20):1618-1623.

7. Kirwin P, Conroy M, Lyketsos C, et al. A call to restructure psychiatry general and subspecialty training. Acad Psychiatry. 2016;40(1): 145-148.

8. Wang PS, Lane M, Olfson M, Pincus HA, Wells KB, Kessler RC. Twelve-month use of mental health services in the United States: results from the National Comorbidity Survey Replication. Arch Gen Psychiatry. 2005;62(6):629-640.

9. Unützer J, Katon W, Callahan CM, et al. Collaborative care management of late-life depression in the primary care setting: a randomized controlled trial. JAMA. 2002;288(22):2836-2845.

10. Nallamothu BK, Hayward RA, Bates ER. Beyond the randomized clinical trial: the role of effectiveness studies in evaluating cardiovascular therapies. Circulation. 2008;118(12):1294-1303.

11. French DD, LaMantia MA, Livin LR, Herceg D, Alder CA, Boustani MA. Healthy aging brain center improved care coordination and produced net savings. Health Aff (Millwood). 2014;33(4):613-618.

12. Callahan CM, Boustani MA, Weiner M, et al. Implementing dementia care models in primary care settings: The Aging Brain Care Medical Home. Aging Ment Health. 2011;15(1):5-12.

13. LaMantia MA, Alder CA, Callahan CM, et al. The Aging Brain Care Medical Home: preliminary data. J Am Geriatr Soc. 2015;63(6): 1209-1213.

14. Alder CA, LaMantia MA, Austrom MG, Boustani MA. The Indiana Aging Brain Care Project. In: Geriatrics Models of Care. Switzerland: Springer International Publishing; 2015:231-237.
15. Cottingham AH, Alder C, Austrom MG, Johnson CS, Boustani MA, Litzelman DK. New workforce development in dementia care: screening for "caring": preliminary data. J Am Geriatr Soc. 2014; 62(7):1364-1368.

16. Austrom MG, Carvell CA, Alder CA, Gao S, Boustani M, LaMantia M. Workforce development to provide person-centered care. Aging Ment Health. 2016;20(8):781-792.

17. Kroenke K, Spitzer RL, Williams JB. The Phq-9. J Gen Intern Med. 2001;16(9):606-613.

18. Monahan PO, Boustani MA, Alder C, et al. Practical clinical tool to monitor dementia symptoms: the HABC-Monitor. Clin Interv Aging. 2012;7:143.

19. Frame A, LaMantia M, Bynagari BBR, Dexter P, Boustani M. Development and implementation of an electronic decision support to manage the health of a high-risk population: the enhanced Electronic Medical Record Aging Brain Care Software (eMR-ABC). eGEMs (Wash DC). 2013;1(1):1009.

20. Thase ME, Frank E, Kornstein SG, Yonkers KA. Gender differences in response to treatments of depression. In: Gender and Its Effects on Psychopathology. Washington, DC: American Psychiatric Press, Inc.; 2000:103-129.

21. Bartels SJ, Naslund JA. The underside of the silver tsunami - older adults and mental health care. $N$ Engl J Med. 2013;368(6):493-496.

22. Institute of Medicine (U.S.). Committee on the Future Health Care Workforce for Older Americans. Retooling for an Aging America: Building the Hhealth Care Workforce. Washington (DC): National Academies Press; 2008.

23. Institute of Medicine (U.S.). Committee on Mental Health Workforce for Geriatric Populations., Eden J, editor. The Mental Health and Substance Use Workforce for Older Adults: In Whose Hands? Washington (DC): National Academies Press; 2012.
Clinical Interventions in Aging

\section{Publish your work in this journal}

Clinical Interventions in Aging is an international, peer-reviewed journal focusing on evidence-based reports on the value or lack thereof of treatments intended to prevent or delay the onset of maladaptive correlates of aging in human beings. This journal is indexed on PubMed Central, MedLine,

\section{Dovepress}

CAS, Scopus and the Elsevier Bibliographic databases. The manuscript management system is completely online and includes a very quick and fair peer-review system, which is all easy to use. Visit http://www.dovepress. com/testimonials.php to read real quotes from published authors. 